Mal J Nutr 25(2): 209-216, 2019

\title{
Overweight and obesity in patients with cancer: study in Dharmais National Cancer Hospital, Jakarta
}

\author{
Noorwati Sutandyo ${ }^{1^{*}} \&$ Ririn Hariani ${ }^{2}$ \\ ${ }^{1}$ Department of Hematology and Clinical Oncology, Dharmais National Cancer Centre \\ Hospital Indonesia; ${ }^{2}$ Department of Clinical Nutrition, Dharmais National Cancer \\ Centre Hospital Indonesia
}

\begin{abstract}
Introduction: Overweight and obesity are considered risk factors for several solid and blood cancers. However, body mass index (BMI) is rarely assessed in newly diagnosed patients with cancer. This study aimed to evaluate BMI and its associated factors in patients with cancer. Methods: This cross-sectional study enrolled newly diagnosed cancer patients over the period January 2015-December 2017 at the Dharmais National Cancer Hospital, Jakarta. Demographic and clinical data were retrieved from the medical records. BMI was calculated for each patient. Comorbidity was evaluated using the Charlson Comorbidity Index. Results: In total, 696 newly diagnosed cancer patients were enrolled, with women in predominance (66.2\%). The mean patient age was $54.0 \pm 12.8$ years. Most patients $(90.7 \%)$ had solid tumours; breast and lung cancers were the most common diagnosis. Among haematological malignancies, lymphoma was the most common (55.4\%). Overweight or obesity, noted in $309(44.4 \%)$ patients, was significantly associated with age, sex (women) and haematological malignancies. No association between disease stage and BMI was observed. Among patients with solid tumours, age and sex (women) was associated with overweight and obesity. Conclusion: The prevalence of overweight and obesity in newly diagnosed cancer patients was $44.4 \%$. The proportion of this association was more prominent in women and in those with haematological malignancies. Among solid tumours, age and the female sex demonstrated the strongest association with overweight and obesity. Additional studies to assess whether certain dietary patterns and physical activity levels are risk factors for cancer are warranted.
\end{abstract}

Keywords: Body mass index, cancer, obesity, overweight

\section{INTRODUCTION}

Globally, 14.1 million new cases of cancer were reported in GLOBOCAN 2012 (Torre et al., 2012) of which $57 \%$ of cases were found in the less developed countries. Data from Riset Kesehatan Dasar Indonesia (Kemkes RI, 2013) showed that the national prevalence of cancer was 1.4 per 1000 or approximately 347,792 persons. Cancer ranks third among the non-communicable diseases in Indonesia, after asthma and chronic obstructive pulmonary disease. Wolin, Carson \& Colditz (2010) found that

\footnotetext{
*Corresponding author: Noorwati Sutandyo, MD

Dharmais National Cancer Centre Hospital, J1. Let. Jend. S. Parman Kav. 84-86,

Slipi, Palmerah, RT.4/RW.9, Kota Bambu Selatan, Palmerah,

Kota Jakarta Barat, Daerah Khusus Ibukota Jakarta, 11420

Tel. No. of Institution: +6221 5681570; Fax No. of Institution: +6221 56969561

Email address: noorwatisoetandyo@gmail.com

doi: https://doi.org/10.31246/mjn-2018-0164
} 
several cancers were associated with obesity, such as endometrial cancer, oesophageal adenocarcinoma, colorectal cancer, breast cancer in postmenopausal women, prostate cancer, and renal cancer. Less common types of cancer that were associated with obesity were melanoma, thyroid cancer, leukaemia, non-Hodgkin lymphoma and multiple myeloma (Lichtman, 2010).

A study by Drake et al. (2017) found that high body mass index (BMI) could increase overall cancer incidence, obesity-related cancer incidence, and cancer-related mortality incidence by $3 \%, 7 \%$, and $5 \%$, respectively. However, another study by Denis \& Palmer (2017) showed that people with high BMI but low inflammation and undisturbed metabolism can have a lower risk of obesity-associated cancer compared with normal weight or slightly overweight (per BMI) individuals with inflammation and metabolic abnormalities.

Until recently, data on the nutritional status of patients with cancer in Indonesia and its associated factors were unavailable. Calculating BMI is an inexpensive and concise method that is used to assess nutritional status in patients. This study assessed the BMI status of patients with cancer at the Dharmais National Cancer Hospital, Jakarta, Indonesia, by using BMI and its associated factors.

\section{MATERIALS AND METHODS}

This was a cross-sectional study undertaken at the Dharmais National Cancer Hospital. It was reviewed and approved by Ethical Committee of the Hospital and given the approval number Indonesia No. 014/KEPK/I/2018. The patients enrolled in this study were newly diagnosed with cancer between January 2015 and December 2017. The inclusion criteria were age $\geq 18$ years, histologically confirmed malignancy from tissue or bone marrow specimens with available data on initial BMI at the time of diagnosis. Demographic and clinical data were retrieved from the medical records of the patient. There were no exclusion criteria. Clinical data that was extracted consisted of disease stage, histopathology type, comorbidity, and BMI which was calculated by dividing body weight $(\mathrm{kg})$ by the square of body height $\left(\mathrm{m}^{2}\right)$. Based on the recommended BMI criteria for the Asian-Pacific region by World Health Organization (WHO), BMI was categorised as underweight $\left(<18.5 \mathrm{~kg} / \mathrm{m}^{2}\right)$, normal $(18.5-22.9 \mathrm{~kg} /$ $\left.\mathrm{m}^{2}\right)$, overweight $\left(23.0-24.9 \mathrm{~kg} / \mathrm{m}^{2}\right)$, or obesity $\left(\geq 25 \mathrm{~kg} / \mathrm{m}^{2}\right)$. The Charlson Comorbidity Index (CCI) was used to assess comorbidity levels.

Descriptive statistics are presented as means and standard deviations for normally distributed variables and as medians and ranges if distribution was skewed. Categorical data are presented as frequency and percentage. Differences in frequencies of variables between groups were analysed using Chi-square or Kolmogorov-Smirnov tests. Differences of means were analysed using the Mann-Whitney U test for skewed data. Associations between variables were considered significant if the $p$-value was <0.05. Data analyses were performed using STATA (version 15.0; STATA Corporation, Texas, USA). Variables with $p<0.25$ in bivariate analysis were included in multivariate analysis.

\section{RESULTS}

During the study period, 696 patients were newly diagnosed with cancer, with women showing predominance at $66.2 \%$ of the total. The median of age of the patients was $55.0 \pm 18.0$ years. Most of the cancers $(90.7 \%)$ were solid tumours, and, breast and lung cancers were the most common diagnoses. Lymphoma 
was the most common malignancy (55.4\%) among haematological cancers. Among the patients, $71.3 \%$ were diagnosed at stage III or IV. Patients with normal BMI were in majority, followed by those classified with obesity (Table 1).

Table 1. Patient characteristics $(n=696)$

\begin{tabular}{lc}
\hline Variable & $n(\%)$ \\
\hline Age group & \\
$\quad<60$ years & $433(62.2)$ \\
$\geq 60$ years & $263(37.8)$ \\
Sex & \\
$\quad$ Women & $461(66.2)$ \\
Men & $235(33.8)$ \\
Cancer group & \\
Solid tumors & $631(90.7)$ \\
Hematological malignancies & $65(9.3)$ \\
Cancer stage & \\
I & $32(4.6)$ \\
II & $139(20.0)$ \\
III & $251(36.1)$ \\
IV & $209(30.0)$ \\
Leukemia $($ no staging) & $27(3.9)$ \\
Unknown & $38(5.5)$ \\
BMI & \\
Underweight $\left(<18.5 \mathrm{~kg} / \mathrm{m}^{2}\right)$ & $80(11.5)$ \\
Normal $\left(18.5-22.9 \mathrm{~kg} / \mathrm{m}^{2}\right)$ & $307(44.1)$ \\
Overweight $\left(23.0-24.9 \mathrm{~kg} / \mathrm{m}^{2}\right)$ & $98(14.1)$ \\
Obese $\left(\geq 25 \mathrm{~kg} / \mathrm{m}^{2}\right)$ & $211(30.3)$ \\
Comorbidity Index $(\mathrm{n}=540)$ & \\
Mild-moderate $(\mathrm{CCI}<5)$ & $288(53.3)$ \\
Severe $(C C I \geq 5)$ & $252(36.2)$ \\
\hline
\end{tabular}

Overweight or obesity was found in $309(44.4 \%)$ patients and were significantly associated with the sex and the cancer type. Overweight and obesity were more common in women than in men, haematological malignancies, patients aged $>60$ years, and those with a CCI of $\geq 5$. No association between disease stage and BMI status was observed (Table 2). Among patients with solid tumours, overweight or obesity was highest among patients with breast cancer $(51.4 \%)$, gynaecological cancers (44.6\%), and lung cancer (41.7\%). Head and neck cancer had the fewest patients with overweight or obesity (Table 3 ).

Multivariate analysis was performed for all variables with $p<0.25$ in bivariate analysis (Table 2). Age, female sex and hematologic cancer were the variables that were significantly associated with overweight and obesity (Table 4). Subanalysis was done in solid tumour group. Age and female sex were significant predictive factors to overweight and obesity, while colorectal cancer was a significant protective factor (Table 5).

\section{DISCUSSION}

Despite its clinical importance in cancer management, the determination of the BMI status of patients with cancer remains limited in Indonesia. In this study, we attempted to identify patterns of nutritional status among patients with cancer, focusing on those whose BMI calculations indicated overweight and obesity. The calculation of BMI is one of several methods of assessing nutritional status. It is simple and inexpensive and is closely related to body fat level, morbidity, and mortality.

Notably, we found overweight or obesity in $>40.0 \%$ of our patients with cancer, regardless of disease stage. Furthermore, the proportion tended to be higher in patients above 65 years of age. Epidemiological data by SamperTernent \& Snih (2012) have shown that the prevalence of obesity among older patients is increasing. However, the 2015 and 2016 National Health and Nutrition Examination Surveys (NHANES) found no significant differences in the prevalence of obesity between younger and older adults (Hales et al., 2017). A study by Kalish (2016) showed that higher total body fat, reduced total 
Table 2. Differences in frequencies between BMI status with respect to age, gender, type and stage of cancers and co-morbidity status $(n=696)$

\begin{tabular}{|c|c|c|c|}
\hline Variable & $\begin{array}{c}\text { Underweight/Normal } \\
n(\%)\end{array}$ & $\begin{array}{c}\text { Overweight/Obese } \\
n(\%)\end{array}$ & $p$-value \\
\hline Age (years) & & & $0.049 *$ \\
\hline$<60$ years & $252(58.2)$ & $181(41.8)$ & \\
\hline$\geq 60$ years & $135(51.3)$ & $128(48.7)$ & \\
\hline \multicolumn{4}{|l|}{ Sex } \\
\hline Male & $148(63.0)$ & $87(37.0)$ & $0.005^{*}$ \\
\hline Female & $239(51.8)$ & $222(48.2)$ & \\
\hline \multicolumn{4}{|l|}{ Cancer Group } \\
\hline Solid tumour & $361(57.2)$ & $270(42.8)$ & $0.008^{*}$ \\
\hline Blood malignancy & $26(40.0)$ & $39(60.0)$ & \\
\hline \multicolumn{4}{|l|}{ Stage of disease $(n=631)$} \\
\hline Stage I - II & 98 (57.6) & $72(42.4)$ & 0.855 \\
\hline Stage III - IV & $262(56.8)$ & $199(43.2)$ & \\
\hline \multicolumn{4}{|l|}{ Comorbidity (n=643) } \\
\hline CCI low-moderate $(<5)$ & $177(61.5)$ & $111(38.5)$ & 0.079 \\
\hline CCI high $(\geq 5)$ & $136(54.0)$ & $116(46.0)$ & \\
\hline
\end{tabular}

${ }^{\dagger}$ Analysis for categorical data using Chi-square or Kolmogorov Smirnov ${ }^{*} p<0.05$

Table 3. Distribution of BMI status according to the type of solid tumour ( $n=531$ )

\begin{tabular}{lccc}
\hline Cancer Type & $\begin{array}{c}\text { Underweight/Normal } \\
n(\%)\end{array}$ & $\begin{array}{c}\text { Overweight/ Obese } \\
n(\%)\end{array}$ & $\begin{array}{c}\text { Total } \\
n(\%)\end{array}$ \\
\hline Breast cancer & $123(48.6)$ & $130(51.4)$ & $253(100.0)$ \\
Lung cancer & $70(58.3)$ & $50(41.7)$ & $120(100.0)$ \\
Gynaecological cancer & $51(55.4)$ & $41(44.6)$ & $92(100.0)$ \\
Colorectal cancer & $52(69.3)$ & $23(30.7)$ & $75(100.0)$ \\
Head and neck cancer & $30(88.2)$ & $4(11.8)$ & $34(100.0)$ \\
Others & $33(60.0)$ & $22(40.0)$ & $55(100.0)$ \\
\hline
\end{tabular}

Table 4. Multivariate analysis of factors associated with overweight and obesity $(n=540)$

\begin{tabular}{lccc}
\hline Variables & OR & $95 \%$ CI & $p$-value \\
\hline Age (years) & 1.02 & $1.00-1.04$ & $0.019^{*}$ \\
Female & 1.82 & $1.23-2.69$ & $0.003^{*}$ \\
Hematologic cancer & 2.96 & $1.61-5.44$ & $<0.001^{*}$ \\
CCI score & 1.06 & $0.96-1.16$ & 0.24 \\
\hline
\end{tabular}

Analysis using multiple logistic regression for categorical data and multiple linear regression for numerical data

${ }^{*} p<0.05$ 
Table 5. Factors associated with overweight and obesity among solid tumour patients $(n=480)$

\begin{tabular}{lccc}
\hline Variables & OR & $95 \%$ CI & -value \\
\hline Age (years) & 1.03 & $1.01-1.05$ & $0.001^{*}$ \\
Female & 1.74 & $1.12-2.71$ & $0.014^{*}$ \\
Colorectal cancer & 0.31 & $0.13-0.73$ & $0.008^{*}$ \\
Stage III-IV & 1.15 & $0.73-1.81$ & 0.556 \\
CCI score & 1.02 & $0.92-1.13$ & 0.683 \\
\hline
\end{tabular}

Analysis using multiple logistic regression for categorical data and multiple linear regression for numerical data

${ }^{*} p<0.05$

energy consumption, altered hormonal and basal metabolic rate, and decreased activity associated with aging could explain the higher prevalence of obesity in older compared to younger adults.

We found a significant positive association between the sex of patients and BMI, with women patients being more likely to be overweight or obese. Less physical activity, impulsive diet habits, and psychosocial factors are some explanations for the higher prevalence of obesity in women, as shown by Kanter $\&$ Caballero (2012). However, data from the NHANES for 2015 and 2016 showed no significant difference in the prevalence of obesity between men and women (Hales et al., 2017).

Our data showed that overweight and obesity were more common among patients with blood cancers than with solid tumours. Lichtman (2010) found that higher BMIs were associated with greater risks for blood cancers, including lymphoma, leukaemia or multiple myeloma. Another study by $\mathrm{Li}$ et al. (2017) found that overweight and obesity could increase the incidence of acute myeloid leukaemia and predict poor outcome.

In our study, breast, gynaecological and lung cancers were among the solid cancers that demonstrated the strongest associations with overweight and obesity. In the United States, data by World Cancer Research Fund/American
Institute for Cancer Research (2017) showed that the most common solid tumours in patients that are associated with obesity are endometrial cancer; oesophageal adenocarcinoma; and colorectal, breast (in postmenopausal women), prostate, and renal cancers. Another study by Davoodi et al. (2013) found that breast, liver, skin, colorectal, ovarian, prostate, renal cell, and endometrial cancer were the solid organ cancers that were strongly associated with obesity.

The association of breast cancer with obesity has been extensively investigated. Chen et al. (2016) found that postmenopausal obese women (BMI $\geq 30$ $\mathrm{kg} / \mathrm{m}^{2}$ ) had an $82 \%$ higher risk of triplenegative breast cancer [i.e. negative for estrogen receptors, progesterone receptors, and excess human epidermal growth factor receptor 2 (HER2) protein] compared with women with BMI $<25$ $\mathrm{kg} / \mathrm{m}^{2}$ (95\% CI: 1.32-2.51). This is attributable to hormonal influences, as the conversion of peripheral androgen into estrogen in adipose tissue is the main source of circulating oestrogen in the postmenopausal term. Another study by Khabaz et al. (2017) found that increased serum leptin concentration was an independent risk factor for breast cancer. Serum leptin, one of the hormones directly connected to body fat and obesity, was also associated with cell growth, invasion, migration, and 
metastasis recurrence in other cancers, such as liver, lung, gastric, thyroid, uterine, and colon cancers.

Tworoger \& Huang (2016) reported an elevated incidence of gynaecological cancers, particularly endometrial and ovarian cancers, among patients who were overweight or obese. A study by Feng (2015) showed that overweight is associated with insulin resistance, adiposity and chronic inflammation, all of which increase the risk of gynaecological cancer. However, the association between obesity and cervical cancer remains controversial. In this study, we found that seven of nine $(77.8 \%)$ patients with endometrial cancer had overweight or obesity. However, only $40.0 \%$ of patients with ovarian or cervical cancer were overweight or obese (data not shown). There was no association between BMI and disease stage. Overweight or obesity was found in exactly $50.0 \%$ of stage III or IV gynaecological cancer cases.

The association between obesity and risk of lung cancer remains inconclusive. In our series, approximately $40.0 \%$ of patients with lung cancer were overweight or obese. A study by Rauscher, Mayne $\&$ Janerich (2000) found that increased BMI was significantly associated with an increased risk of lung cancer in both smokers and non-smokers. However, other studies by Duan et al. (2015) \& Yang et al. (2013) have shown different results, such as overweight being a protective factor against lung cancer. This is supported by a study by Patel et al. (2017) which found that BMI was not associated with the development of lung cancer.

Our study showed no association between BMI and disease stage in major cancer types (data not shown). Notably, $>40.0 \%$ of patients in advanced stages, except the patients with colorectal cancer who had mostly normal or low BMIs, were overweight or obese. A study of patients with breast cancer by Cui et al. (2002) found that high BMI was significantly associated with the late stage of breast cancer. Women with obesity $\left(\mathrm{BMI}>27.3 \mathrm{~kg} / \mathrm{m}^{2}\right)$ had a more advanced stage when first diagnosed compared with women with a BMI of $<27.3 \mathrm{~kg} / \mathrm{m}^{2} \quad$ (multivariate-adjusted odds ratio, $\mathrm{OR}=1.57$; 95\% CI: $1.15-2.14)$. Muscaritoli et al. (2017) \& Wie et al. (2010) showed that malnutrition is more commonly found in the advanced stages of cancer. However, study by Prasad et al. (2010) showed that malnutrition should be diagnosed not only based on BMI but also by considering changes in body weight and applying laboratory examinations of malnutrition screening tools.

In this study, severe comorbidity $(\mathrm{CCI} \geq 5)$ was more common in patients with overweight and obesity. To our knowledge, no study has directly assessed the association of comorbidity and BMI in patients with cancer. PiSunyer (2009) found that obesity is a known risk factor for several diseases, including diabetes, stroke, cardiovascular disease, osteoarthritis, liver and renal disorders, sleep apnea, and depression. Other studies by Prasad et al. (2010) and Takenaka et al. (2014) that have evaluated the nutritional status of patients with and without cancer have found malnutrition to be more common in patients with higher CCI. However, these results remain unexplained.

Several major mechanisms may explain the association between obesity and cancer as stated by Berger (2014) and Pergola \& Silvestris (2013), such as increased growth factor levels and bioavailability; increased steroid sex hormones (e.g. oestrogen); altered adipocytokine levels; inflammation and oxidative stress, which influence the cytokines and immune modulation; and changing microbiomes, particularly that of intestinal flora. Excesses of body weight and adipocytes are directly 
associated with insulin resistance. Hyperinsulinemia, as compensation for pancreas stimulation, would accelerate growth and increase the aggressiveness of colorectal, pancreatic, liver, (postmenopausal) breast, and endometrial cancers. Insulin possesses an anabolic and anti-apoptotic effect. Most cancer cells are able to respond to the insulin activation effect through the intracellular transduction pathway. Hyperinsulinemia could increase the synthesis of insulin-like growth factor 1 (IGF-1) and decrease the expression of its binding protein. IGF-1 also has a proangiogenic effect and induces tumourrelated lymphangiogenesis.

This study had some limitations. First, we did not analyse metabolic or nutritional factors related to high BMI because these assessments were not part of routine diagnostic workups in our hospital and thus were not recorded. Second, we could not assess obesity as a risk factor for certain cancers because of the cross-sectional design of our study. However, the results may provide a general picture of BMI status of patients with cancer, which could be affected by eating patterns and physical activity. Future studies to elaborate the associations between energy intake and physical activity and cancer risk are warranted.

\section{CONCLUSION}

The prevalence of overweight and obesity among patients with cancer was $44.4 \%$. Overweight and obesity were more prevalent in older age, women and in those with haematological malignancies. They were associated with age and female sex among those with solid tumours and were most common in patients with breast, gynaecological, and lung cancers. Further study is required to assess whether certain dietary patterns and levels of physical activity are risk factors for cancer.

\section{Acknowledgements}

We thank the Director of Dharmais Cancer Hospital, the Head of the Research Division of Dharmais Cancer Hospital and the Head of the Medical Records Division at Dharmais Cancer Hospital, who gave their permission to conduct this study. We would also like to thank Wallace Academic Editing for editing this manuscript.

\section{Authors' contributions}

Both NS (principal investigator) and $\mathrm{RH}$ conceptualised and designed the study, prepared the draft of manuscript, conducted data collection and reviewed the manuscript.

\section{Conflict of interest}

We declare that we have no conflict of interest. This research did not receive any specific grant from funding agencies in the public, commercial or not for profit sectors.

\section{References}

Berger NA (2014). Obesity and cancer pathogenesis. Ann N Y Acad Sci 1311:57-76.

Chen L, Cook LS, Tang MTC, Porter PL, Hill DA, Wiggins CL \& Li CI (2016). Body mass index and risk of luminal, HER2-overexpressing, and triple negative breast cancer. Breast Cancer Res Treat 157:545-54.

Cui Y, Whiteman MK, Flaws JA, Langenberg P, Tkaczuk KH \& Bush TL (2002). Body mass and stage of breast cancer at diagnosis. Int. $J$ Cancer 98:279-83.

Davoodi SH, Malek-Shahabi T, MalekshahiMoghadam A, Shahbazi R \& Esmaeili S (2013). Obesity as an important risk factor for certain types of cancer. Iran J Cancer Prev 6:186-94.

Denis GV \& Palmer JR (2017). Obesity-associated breast cancer in lean women: metabolism and inflammation as critical modifiers of risk. Cancer Prev Res (Phila) 10:267-9.

Drake I, Gullberg B, Sonestedt, Stocks T, Bjartell A, Wirfalt E, Wallström P \& Orho-Melander M (2017). Type 2 diabetes, adiposity and cancer morbidity and mortality risk taking into account competing risk of noncancer deaths in a prospective cohort setting. Int $J$ Cancer 141:1170-80. 
Duan P, Hu C, Quan C, Yi X, Zhou W, Yuan M, Yu T, Kourouma A \& Yang K (2015). Body mass index and risk of lung cancer: systematic review and dose-response meta-analysis. Sci Rep 5:16938.

Feng YH (2015). The association between obesity and gynecological cancer. Gynecol Minimally Invasive Ther 4:102-5.

Hales CM, Carroll MD, Fryar CD \& Ogden CL (2017).Prevalence of obesity among adults and youth: United States, 2015-2016. NCHS Data Brief. No. 288. From: http://www.cdc.gov/ nchs/data/databriefs/db288.pdf. [Retrieved September 10 2018].

Kalish VB (2016).Obesity in older adults. Prim Care Clin Office 43:137-44.

Kanter R \& Caballero B (2012). Global gender disparities in obesity: a review. Adv Nutr 3: 491-8.

Kemkes RI (2013). Riset Kesehatan Dasar 2013. Badan Penelitian dan Pengembangan Kesehatan, Kementrian Kesehatan Republik Indonesia, Jakarta.

Khabaz MN, Abdelrahman A, Butt N, DamnhoryL, Elshal M, Aldahlawi AM, Ashoor S, AlMaghrabi B, Dobson P, Brown B, Al-Sakkaf K, Al-Qahtani M \& Al-Maghrabi J (2017). Immunohistochemical staining of leptin is associated with grade, stage, lymph node involvement, recurrence, and hormone receptor phenotypes in breast cancer. BMC Women's Health 17:105.

Li S, Chen L, Jin W, Ma X, Ma Y, Dong F, Zhu H, Li J \& Wang K (2017). Influence of body mass index on incidence and prognosis of acute promyelocytic leukemia: a meta-analysis. Sci $\operatorname{Rep~7:17998.~}$

Lichtman MA (2010). Obesity and the risk for a hematological malignancy: leukemia, lymphoma or myeloma. Oncologist 15:1083101.

Muscaritoli M, Lucia S, Farcomeni A, Lorusso V, Saracino V, Barone C, Plastino F, Gori S, Magarotto R, Carteni G, Chiurazzi B, Pavese I, Marchetti L, Zagonel V, Bergo E, Tonini G, Imperatori $\mathrm{M}$, Iacono $\mathrm{C}$, Maiorana $\mathrm{L}$, Pinto $\mathrm{C}$, Rubino D, Cavanna L, Di Cicilia R, Gamucci T, Quadrini S, Palazzo S, Minardi S, Merlano M, Colucci G, Marchetti P \& PreMiO Study Group (2017). Prevalence of malnutrition in patients at first medical oncology visit: the PreMiO study. Oncotarget 8:79884-96.
Patel AV, Carter BD, Stevens VL, Gaudet MM, Campbell PT \& Gapstur SM (2017). The relationship between physical activity, obesity, and lung cancer risk by smoking status in a large prospective cohort of US adults. Cancer Causes Control 28:1357-68.

Pergola GD \& Silvestris F (2013). Obesity as a major risk factor for cancer. J Obes 2013:291546.

Pi-Sunyer X (2009). The medical risks of obesity. Postgrad Med 121:21-33.

Prasad N, Gupta A, Sinha A, Sharma RK, Saxena A, Kaul A, Bhaduri D \& Gupta A (2010). Confounding effect of comorbidities and malnutrition on survival of peritoneal dialysis patients. J Renal Nutr 20:384-91.

Rauscher GH, Mayne ST \& Janerich DT (2000). Relation between body mass index and lung cancer risk in men and women never and former smokers. Am J Epid 152:506-13.

Samper-Ternent R \& Snih SA (2012). Obesity in older adults: epidemiology and implications for disability and disease. Rev Clin Gerontol 22:10-34.

Takenaka Y, Yamamoto M, Nakahara S, Yamamoto Y, Yasui T, Hanamoto A,TakemotoN, Fukusumi T, Michiba T, Cho H \& Inohara H (2014). Factors associated with malnutrition in patients with head and neck cancer. Acta Otolaryngol 134:1079-85.

Torre LA, Bray F, Siegel RL, Ferlay J, LortetTieuleunt J \& Jemal A (2012). Global cancer statistics, 2012. CA Cancer J Clin 65:87-108.

Tworoger SS \& Huang T (2016). Obesity and ovarian cancer. Recent Results Cancer Res 208:155-76.

Wie GA, Cho YA, Kim SY, Kim SM, Bae JM \& Joung $H$ (2010).Prevalence and risk factors of malnutrition among cancer patients according to tumor location and stage in the National Cancer Center in Korea. Nutrition 26:263-8.

Wolin KY, Carson K \& Colditz GA (2010). Obesity and cancer. Oncologist 15:556-65.

World Cancer Research Fund/American Institute for Cancer Research (2017). Food, nutrition, physical activity, and the prevention of cancer: a global perspective. $2^{\text {nd }}$ ed. American Institute for Cancer Research. Washington, DC.

Yang Y, Dong J, Sun K, Zhao L, Zhao F, Wang L \& Jiao Y (2013). Obesity and incidence of lung cancer: a meta-analysis. Int $J$ Cancer 132:1162-9. 